\title{
A tentative approach to the molecular structure of humic acids: The spectral evidence for a derivation of humic acids from plant-borne esters. 1. The electron paramagnetic resonance (EPR) spectra
}

\section{G. Minderman}

Research Institute for Nature Management, Arnhem, the Netherlands

Accepted: 29 September 1978

Key words: humic acids, spectrophotometry, electron spin resonance, electron paramagnetic resonance, tannin

\section{Summary}

There are many controversies in literature about how to designate EPR ${ }^{1}$ spectra of humic acids, which are not solved in this article either. In humic acids from podzol- $\mathrm{B}_{\mathrm{h}}$ it is possible to show a hyperfine structure in the EPR spectrum, which is absent in humic acids of other origin. Just as tannins, all humic acids show a spectrum which confirms the presence of radicals. Oxidation and reduction symptoms in humic acids and in tannins are simultaneously found back in the EPR spectra. According to these results hydrolysable and condensed tannins enable us to understand the construction of humic acids. In the group of hydrolysable tannins there are a number of compounds in green and brown leaves which, before and after condensation, by mineral acids, are greatly similar to the EPR spectra of humic acids. These substances consist of hexahydroxydiphenic acid esterified with glucose. The conclusion is that humic acids do not contain quinones but should be considered as heterogeneous polymers of mixed esters or tannins.

\section{Introduction}

Since the first publication about the presence of radicals in plant constituents and related other natural substances (Commoner et al., 1954) much has also been written about this symptom in humic acids. The conclusions are by no means identical. The regular presence or absence of a hyperfine structure in the EPR spectra of these substances is still under discussion. The character of the existing radicals and the relation between those of the humic acids and those of the natural constituents, found in living or dying foliage, is still under discussion. Given the

1 Electron paramagnetic resonance (= electron spin resonance). 
analyses of a number of well-purified humic acids of very different origin and of tanning materials and other plant constituents more easily accessible for chemical analyses than humic acids and which still show analogous spectral behaviour, efforts have been made to draw up - from ours and other observations already published a structural plan of the humic acid.

\section{Literature survey}

Commoner et al. (1954) showed stable, free radicals with a spectrum breadth of about $5.5 \mathrm{G}^{2}$ in biological materials, such as melanin, plant gum, resins, humic substances prepared from proteins, coal and tar. These observed radicals have unlimited stability: some may stand heating or reflux with $\mathrm{HCl}$. The unpaired electrons exist when condensed ring products are formed in the plant after the free electrons are caught in the polymer network of the molecules and, as a result, are stabilized. With increasing size the condensed ring system takes up more electrons and consequently forms ever stronger radicals. Besides the stable free radicals, heatsensitive radicals are found in the living plant connected with proteins and occurring during the germination process and then showing a dependence on the degree of illumination. It is highly probable that all the free radicals formed come into existence by radiation of biological systems. Hinney (1972) and Slavinska et al. (1975) believe that they have recently been able to prove the existence or increasing strength of radicals in dead plant constituents through the action of light. Steelink (1964) supposes that, in humic acids, the free radicals are an integral part of the natural macromolecule either shielded by the polymetric network or stabilized by delocalization of the unpaired electron over a suitable aromatic system. Atherton et al. (1967) think that 'the peculiar stability of the radical may be due to association with an extended conjugated system'. Just as Steelink (1965) they argue that humic acid itself is the radical or a mixture of free radicals, in contrast to Rex (1960) who thinks that low-molecular radicals have been caught in an inert polymer network, which has been denied by Steelink et al. (1962, 1963). Hyperfine EPR structures come into existence in solutions, but are lacking in solid substances. Atherton et al. (1967) observed the hyperfine structures in EPR spectra in a number of humic acids after boiling with $6 \mathrm{~N} \mathrm{HCl}\left(\mathrm{ABHA}^{3}\right)$ Class I, in which Riffaldi \& Schnitzer (1972b) were never successful. This symptom never occurs in ABHA, Class II; the spectrum then consists of a smooth curve, as with Riffaldi. Atherton et al. believe that the hyperfine structure is tied down to a low $\mathrm{pH}$ during formation in the soil. With Commoner et al. all research workers agree that, in humic acids, the free radicals are of a semi-quinone or a quinone type, though Steelink \& Tollin (1962) state that the nature of the radicals is rather uncertain and possibly consists of a mixture of the common semi-quinone radical and electron transfer complexes of the quinhydron type. The presence of oxygen affects the spin concentration in alkaline solutions of humic acids. Atherton et al. think that the EPR signal disappears in

$21 \mathrm{G}$ (gauss) $=10^{-4} \mathrm{~T}$ (tesla). The tesla is the SI unit.

3 Acid-boiled humic acid (Burges \& Latter, 1960). 
case of reduction with dithionite and comes back again after airing. Besides, excessive oxygen decreases the strength of the signal, while lack of $\mathrm{O}_{2}$ decreases the resolution in the hyperfine structure of the spectrum. According to Tollin \& Steelink (1966), common air oxydation would not play an important role in the enzymatic formation of free radicals in substances such as tannin and polymer obtained from catechin. In dissolved humic acids Riffaldi \& Schnitzer (1972a,b) found a higher spin concentration than in humic acids in a solid form. In solutions the spin concentration increases in the presence of $\mathrm{O}_{2}$. Their idea that the spin concentration shows a relation with the $\mathrm{H}$ and $\mathrm{O}$ content in the molecule, is not convincing. The spin concentration also increases when certain substances, such as lignin, are ground intensively (Kleinert \& Morton, 1962). In the research of Atherton et al. (1967) chemical and enzymatical artificially prepared humic acids do not agree spectroscopically with natural humic acids.

Summarizing the literature: 1) the presence of free radicals in plant constituents and humic acids has been shown clearly; 2) the irradiated energy (light) influences the existence of these radicals; 3 ) the place of the radical in the humic acid is unknown, just as the nature of the bonds which are responsible; 4) the influence of oxygen and reductors upon the spin concentration and upon the spectrum cannot be explained from the molecular data; 5) the presence of a hyperfine structure in the EPR spectrum is further not generally recognized.

\section{Materials and methods}

The humic acids in question have been extracted from the soil by $0.1 \mathrm{~N} \mathrm{NaOH}$; whether acid treatment $(1 \mathrm{~N} \mathrm{HCl})$ was applied in advance, depended on the soil type. Preparations with a low ash content are wanted, so the humic acids have been precipitated several times from the solution, centrifuged $(18000 \mathrm{rev} / \mathrm{min})$, redissolved, etc. HF $1 N$ with $\mathrm{HCl} 1 N$ has also been used, according to requirement. The preparations used are mainly:

- humic acids originating from:

a) podzol $B_{h}$. Heath soil, Deelen (Netherlands);

b) dopplerite, peat;

c) calcareous mull, black brook earth soil, calcareous, Hackfort forest (Netherlands);

d) chernozem, Oxbow (Canada);

- phlobaphenes (prepared by boiling the basic substances for 1 hour under reflux with $4 \mathrm{~N} \mathrm{HCl}$ ) from:

a) mimosa tannin;

b) dl-catechin;

- plant constituents:

a) lignin (Brauns' lignin, 'Meadol');

b) extracts from oak leaves;

c) isolated substances from oak leaves by thin-layer-chromatography.

(For details see legend to the spectra.)

Parts of the preparations were boiled with $6 \mathrm{~N} \mathrm{HCl}$ for 24 hours, analogous to the process to obtain the ABHA of Burges \& Latter (1960). To remove lignin, an 
Table 1. Spectral data.

\begin{tabular}{|c|c|c|c|c|c|c|c|c|c|c|}
\hline $\begin{array}{l}\text { Figure } \\
\text { No }\end{array}$ & $\begin{array}{l}\text { Gain } \\
\left(x 10^{5}\right)\end{array}$ & $\begin{array}{l}\text { Modulation } \\
\text { amplitude } \\
\text { (G) } 1\end{array}$ & $\begin{array}{l}\text { Time } \\
\text { constant }\end{array}$ & $\begin{array}{l}\text { Frequency } \\
(\mathrm{MHz})\end{array}$ & $\begin{array}{l}\text { Power } \\
(\mathrm{mW})\end{array}$ & $\begin{array}{l}\text { Field set } \\
\text { (G) } 1\end{array}$ & & $\begin{array}{l}\text { Scan } \\
\text { time } \\
\text { (min.) }\end{array}$ & $\begin{array}{l}\text { Split- } \\
\text { ting } \\
\text { factor }\end{array}$ & $\begin{array}{l}\text { Spectrum } \\
\text { width total } \\
\text { (G) } 1\end{array}$ \\
\hline 1 & 8 & 0.02 & 1 & 9490 & 4 & $3375 \pm$ & \pm 5 & 8 & 2.0084 & $4.2-11.0$ \\
\hline 2 & 2 & 0.02 & 0.3 & 9483 & 4 & $3378 \pm$ & \pm 10 & 4 & 2.0056 & $2.2-5.0$ \\
\hline 3 & 10 & 0.016 & 3.0 & 9457 & 4 & $3371 \pm$ & \pm 5 & 8 & 2.0042 & - \\
\hline 4 & 5 & 0.2 & 0.3 & 9457 & 4 & $3370 \pm$ & \pm 5 & 4 & 2.0050 & $1.8-4.0$ \\
\hline 5 & 1.25 & 1.0 & 0.1 & 9457 & 4 & 3370 & \pm 10 & 2 & 2.005 & $2.3-4.5$ \\
\hline 6 & 10 & 0.032 & 1.0 & 9458 & 4 & $3370 \pm$ & \pm 5 & 8 & 2.0051 & - \\
\hline 7 & - & - & - & - & - & 一 & & - & - & - \\
\hline 8 & 10 & 0.02 & 3.0 & 9458 & 2 & $3370 \pm$ & \pm 5 & 4 & 2.005 & - \\
\hline 9 & 10 & 0.08 & 3.0 & 9457 & 2 & $3370 \pm$ & \pm 5 & 8 & 2.0045 & 一 \\
\hline 10 & 10 & 0.8 & 3.0 & 9456 & 2 & $3370 \pm$ & \pm 5 & 8 & 2.0043 & - \\
\hline 11 & 2.5 & 2 & 0.3 & 9458 & 250 & $3370 \pm$ & \pm 5 & 4 & 2.0051 & $5.5-12.5$ \\
\hline 12 & 2 & 0.08 & 0.3 & 9457 & 4 & $3371 \pm$ & \pm 5 & 4 & 2.0042 & - \\
\hline 13 & 2 & 0.02 & 0.3 & 9455 & 0.25 & $3371.5 \pm$ & \pm 5 & 4 & 2.0035 & - \\
\hline 14 & 2 & 0.02 & 0.3 & 9456 & 1 & $3371.5 \pm$ & \pm 5 & 4 & 2.0037 & - \\
\hline 15 & 10 & 0.02 & 3 & 9458 & - & - & & - & - & - \\
\hline 16 & 15 & 0.4 & 3 & 9456 & 2 & $3360.6 \pm$ & \pm 10 & 8 & 2.0043 & - \\
\hline 17 & 10 & 0.02 & 3 & 9458 & 2 & $3370.5 \pm$ & \pm 5 & 4 & 2.005 & - \\
\hline 18 & 10 & 0.08 & 1 & 9556 & 1.25 & $3371.5 \pm$ & \pm 5 & 8 & 2.0043 & - \\
\hline 19 & 10 & 0.08 & 1 & 9557 & 1.25 & $3371.5 \pm$ & \pm 5 & 8 & 2.0045 & - \\
\hline 20 & 10 & 0.08 & 1 & - & - & $3371.5 \pm$ & \pm 5 & 8 & - & - \\
\hline 21 & 4 & 0.04 & 1 & 9458 & 4 & $3371.5 \pm$ & \pm 5 & 4 & 2.0041 & - \\
\hline 22 & 10 & 0.08 & 3 & 9457.5 & 4 & $3371.5 \pm$ & \pm 5 & 8 & 2.004 & - \\
\hline 23 & 10 & 0.1 & 3 & 9458 & 2 & $3370.6 \pm$ & \pm 10 & 16 & 2.005 & - \\
\hline 24 & 25 & 0.25 & 10 & 9489.5 & 4 & $3375 \pm$ & $\pm 10 ?$ & 30 & 2.0086 & ca.1.9- 7.0 \\
\hline 25 & 12.5 & 0.4 & 3 & 9456 & 4 & 3372 & \pm 10 & 8 & 2.0019 & $2.9-10.5$ \\
\hline 26 & 6 & 0.25 & 1 & 9489.5 & 4 & $3375 \pm$ & \pm 10 & 21 & 2.0086 & $4.2-11.0$ \\
\hline 27 & 2.5 & 0.08 & 0.3 & 9490 & 4 & $3375 \pm$ & \pm 10 & 4 & 2.0086 & $2.4-10.0$ \\
\hline 28 & 10 & 0.125 & 3.0 & 9490 & 4 & $3375 \pm$ & \pm 5 & 8 & 2.0084 & - \\
\hline 29 & 40 & 0.1 & 10 & 9457 & 4 & 3370 & \pm 10 & 16 & 2.005 & $3.1-10.5$ \\
\hline 30 & 20 & 1 & 3 & 9457 & 4 & $3370 \pm$ & \pm 10 & 8 & 2.0051 & $2.1-8$ \\
\hline 31 & 1.5 & 1 & 3 & 9458 & 4 & 3370 & \pm 10 & 8 & 2.0051 & $2.3-10.5$ \\
\hline 32 & 25 & 0.2 & 10 & 9458 & 4 & 3372 & \pm 10 & 16 & 2.0023 & $2.4-8$ \\
\hline 33 & 3.2 & 0.5 & 10 & 9489 & 4 & $3375 \pm$ & \pm 5 & 30 & 2.0083 & $2.2-8$ \\
\hline 34 & 2 & 0.2 & 10 & 9458 & 4 & $3370 \pm$ & \pm 10 & 30 & 2.0051 & $2.2-9.5$ \\
\hline 35 & 12.5 & 0.2 & 3 & 9458 & 4 & $3370 \pm$ & \pm 10 & 8 & 2.0051 & $2.5-9$ \\
\hline 36 & 20 & 0.2 & 3 & 9457 & 4 & $3370 \pm$ & \pm 10 & 8 & 2.0050 & - \\
\hline 37 & 20 & 0.4 & 3 & 9458 & 4 & $3370 \pm$ & \pm 10 & 8 & 2.0051 & - \\
\hline 38 & - & 一 & - & - & - & - & & - & - & $8-40$ \\
\hline 39 & 5 & 0.4 & 0.3 & 9221 & 4 & 3269 & \pm 5 & 8 & 2.0149 & ca. 5 \\
\hline 40 & 1.25 & 2 & 1.0 & 9221 & 4 & $3269 \pm$ & \pm 10 & 8 & 2.0149 & ca.7 \\
\hline 41 & 20 & 0.4 & 1.0 & 9221 & 4 & 3269 & \pm 10 & 8 & - & - \\
\hline 42 & 12.5 & 0.4 & 1.0 & 9221 & 4 & $3269 \pm$ & \pm 10 & 8 & - & - \\
\hline 43 & 20 & 2.0 & 3.0 & 9221 & 4 & $3269 \pm$ & \pm 10 & 8 & - & ca. 5 \\
\hline 44 & 20 & 0.4 & 1.0 & 9221 & 4 & $3269 \pm$ & \pm 10 & 8 & - & - \\
\hline 45 & 20 & 0.4 & 3.0 & 9221 & 4 & $3269 \pm$ & \pm 10 & 8 & - & - \\
\hline 46 & 10 & 2.0 & 1.0 & 9221 & 4 & $3269 \pm$ & \pm 10 & 8 & - & - \\
\hline 47 & 5 & 0.4 & 1.0 & 9223 & 4 & $3269 \pm$ & \pm 10 & 8 & 2.0149 & ca. 4 \\
\hline 48 & 8 & 0.1 & 0.3 & 9222 & 4 & $3269 \pm$ & \pm 5 & 8 & 2.0147 & 3 \\
\hline 49 & 12.5 & 0.1 & 一 & 9218 & 4 & $3269 \pm$ & \pm 10 & 8 & 2.0139 & 2 \\
\hline 50 & 10 & 0.1 & 1.0 & 9458 & 4 & $3370 \pm$ & \pm 10 & 30 & 2.0051 & - \\
\hline
\end{tabular}

$11 \mathrm{G}$ (gauss) $=10^{-4} \mathrm{~T}$ (tesla). 
other part was boiled in $2 \% \mathrm{HNO}_{3}$ for 3 hours. This affects the humic acids and the cellulose only little (Hisey, 1946). A third part was, according to Halse's method, treated with a mixture of 4 vol. $\mathrm{HCl} 38 \%$ with 1 vol. $\mathrm{H}_{2} \mathrm{SO}_{4}$ conc. for 24 hours at room temperature to remove cellulose and other carbohydrates (Brauns, 1952). For the EPR measurements, the substance was, for a single time, used in powder form; as a rule, the substances were dissolved in $0.1 \mathrm{~N} \mathrm{NaOH}$. The measurements were taken at room temperature, a few powders also at $77 \mathrm{~K}$. To determine the EPR spectra a Varian Ass. E 3 spectrometer with $100 \mathrm{kHz}$ modulation was used and an operating frequency of $9.5 \mathrm{GHz}$. The field strength and the frequency were further kept as constant as possible. Modulation amplitude, power, gain and time constancy were varied. Spin concentrations were not calculated. To allow conclusions to be drawn, the spectrograms were mutually evaluated by comparison (Table 1).

\section{Results}

\section{Lignin}

Meadol (Brauns, 1952) untreated powder gives, with a gain of $8 \times 10^{5}$, many clear double-topped signals (Fig. 1). The form of the signal greatly deviates from all the following spectra of natural substances, phlobaphenes and humic acids. It resembles more or less that of the stable phenoxy radicals derived from phenols (Steelink, 1965).

\section{Humic acids}

The well-purified humic acid of the podzol $\mathrm{B}_{\mathrm{h}}$-horizon and its acid-boiled form show the radical character (Figs 2 and 3). ABHA $\left(\mathrm{B}_{\mathrm{h}}\right)$ in $1 N \mathrm{NaOH}$ (Fig. 4) shows a hyperfine structure. The size of the modulation amplitude causes differences in the form of the spectrum: higher values give a simpler spectrum (Fig. 5). The hyperfine structure of the spectrum continues to exist after prolonged flushing of argon through the alkaline solution as a result of which the other dissolved gases are driven out. By flushing with oxygen, the amplitude greatly declines (Fig. 7), which is in comformity with the observations of Atherton et al. (1967) but contradictory to that of Riffaldi \& Schnitzer (1972b). It was also found in the present research that there is a decline in the fine structure (Figs 4, 7, 11 and 19), whereas sometimes, with a high concentration of the dissolved substance in strong alkaline solution, there is no decline (Figs 12 and 17). Consequently, there seems to be a relation between power, concentration and titre. This can be restored somewhat by increasing the gain; the signal, however, remains weak and without much form. By adding $\mathrm{H}_{2} \mathrm{O}_{2}$, a weak 'argon-flushed' spectrum comes back (Fig. 8) which, after two hours, has become very weak again (Fig. 9). If dithionite is added afterwards, an 'argon-flushed' spectrum without hyperfine structure (Fig. 10) exists just as described by Atherton et al. But the amplitude height also decreases and the spectrum becomes double-topped (Figs 4, 6 and 10) which may also take place after adding $\mathrm{H}_{2} \mathrm{O}_{2}$ (Fig. 9). The spectrum of ABHA in $1 \mathrm{~N} \mathrm{NaOH}$ (Fig. 4) is rather identical with that originating from pure humic acids in $1 N \mathrm{NaOH}$ (Fig. 3). In 
observed (Fig. 13); at $4 \mathrm{~mW}$ (Fig. 12) the details are not clearly observed, and at $250 \mathrm{~mW}$ the details have gone entirely (Fig. 11). The influence of oxygen, for example, by exposing the $1 \mathrm{~N} \mathrm{NaOH}$ solution to air for a long time (1 night), can also be observed in the spectra (Fig. 14). There is a hyperfine structure (Fig. 15) in humic acids- $\mathrm{B}_{\mathrm{h}}$-podzol dissolved in $4 \mathrm{~N} \mathrm{NaOH}$ which is reinforced by flushing with argon (Fig. 16). Flushing with oxygen does not remove this but slightly changes the form of the spectrum (Fig. 17). Everything is different in concentrated solutions of humic acids- $\mathrm{B}_{\mathrm{h}}( \pm 3 \%)$ in diluted $\mathrm{NaOH}(0.1 N)$. No hyperfine structures appear after flushing with argon (Fig. 18), $\mathrm{O}_{2}$ (Fig. 19) or air (Fig. 20). If the solution is diluted by adding $0.1 \mathrm{~N} \mathrm{NaOH}$ and flushed with air, a spectrum with a hyperfine structure (Fig. 21) exists which again disappears by flushing with oxygen, after which a smooth curve remains (Fig. 22). Humic acids- $\mathrm{B}_{\mathrm{h}}$ dissolved in a mixture of dimethyl sulfoxide with a little trimethanolamin show a spectrum with little or no hyperfine structure (Fig. 23). It seems that, besides the obtained power, the development of hyperfine structures in humic acids from podzol- $\mathrm{B}_{\mathrm{h}}$ greatly depends on the relation between concentration dissolved substance and concentration $\mathrm{NaOH}$. With humic acids from dopplerite we could not find a hyperfine structure in any way. In the pure substance, dissolved in $1 \mathrm{~N} \mathrm{NaOH}$, it was even difficult to get a curve (Fig. 24). The latter without more applies to preparations obtained after acid treatment of the purified dopplerite humic acid (after treatment according to Halse (Fig. 25) and after $6 \mathrm{~N} \mathrm{HCl)} \mathrm{(Fig.} \mathrm{26),} \mathrm{preparations}$ which, in contrast to those of other humic acids, dissolve well in diluted $\mathrm{NaOH}$. A hyperfine structure does not develop in the EPR spectra. If, after treatment with $2 \% \mathrm{HNO}$, dopplerite-ABHA is dissolved in $\mathrm{NaOH}$ solution, a very high curve shows up (Fig. 27); after dithionite is added a double-topped spectrum exists (Fig. 28) somewhat resembling $\mathrm{B}_{\mathrm{h}}-\mathrm{ABHA}$ after dithionite (Fig. 10). It seems as if, in dopplerite, the acid treatment greatly reinforces the signal and marks it more strongly in case of equal modulation amplitude and power. This also is the case in humic acids of Oxbow and Hackfort, where, however, nothing can be observed of a hyperfine structure (Fig. 29 and 30), nor after $6 \mathrm{~N} \mathrm{HCl}$ (Figs 31 and 32).

\section{The phlobaphenes}

A well-known tannin used in leather dressing is mimosa powder, originating from the wood and the bark of Acacia mollissima and A. decurrens (Hathway, 1962). Dissolved in $0.1 \mathrm{~N} \mathrm{NaOH}$, this substance gives a clear EPR signal, though with very little hyperfine structure (Fig. 33). After boiling with $4 \mathrm{~N} \mathrm{HCl}$ or $2 \mathrm{~N} \mathrm{H}_{2} \mathrm{SO}_{4}$ for one hour, this substance has been converted into an insoluble condensate called phlobaphene. Its $\mathrm{NaOH}$ solution gives a spectrum with very clear hyperfine structures (Fig. 34) such as catechin also shows after similar treatment (Fig. 35); it then strongly resembles $\mathrm{ABHA}_{\mathrm{h}}$ (Fig. 4). After boiling with $2 \% \mathrm{HNO}_{3}$ (Figs 36 and 37 ), the fine structures in these phlobaphenes, obtained from catechin and mimosa powder disappear while the curves become flatter. If this spectral change in the mimosa could be the result of the removal of lignin through nitric acid, the structure should not reappear after adding dithionite, whereas this phenomenon, however, does take place (Fig. 38). In catechin any presence of lignin is out of the 


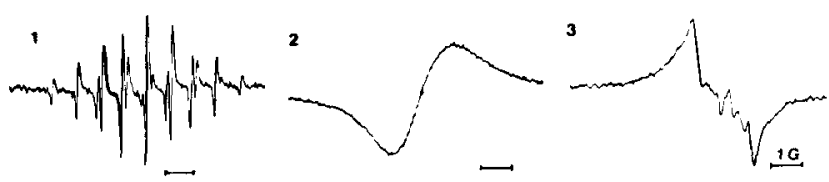

Domprom

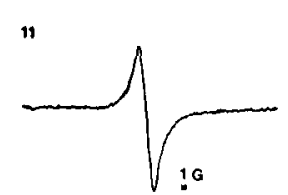

16<smiles>[C]1CCCC1</smiles>

14

26
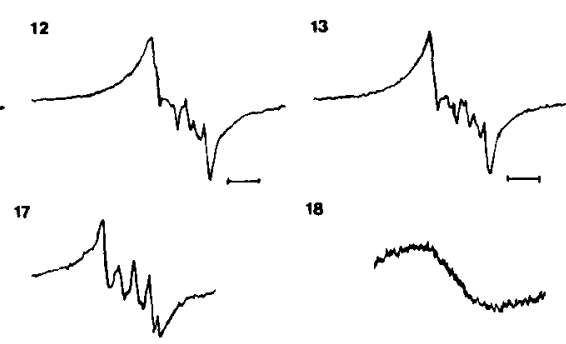

18

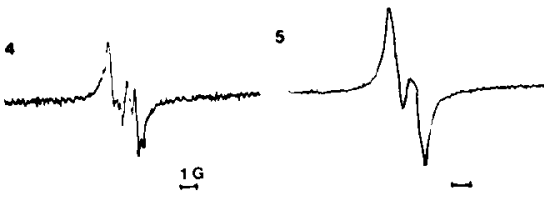

9

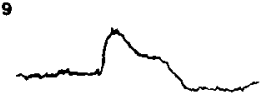

10

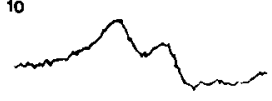

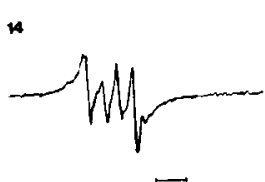

15

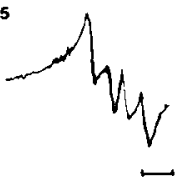

19
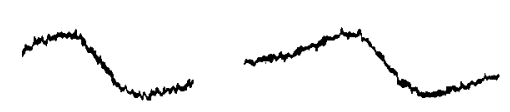

20

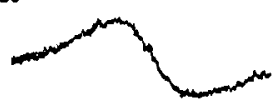
22
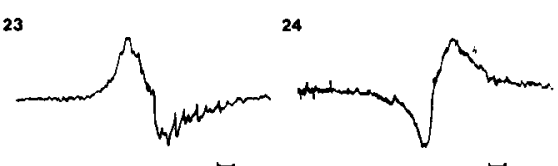

25
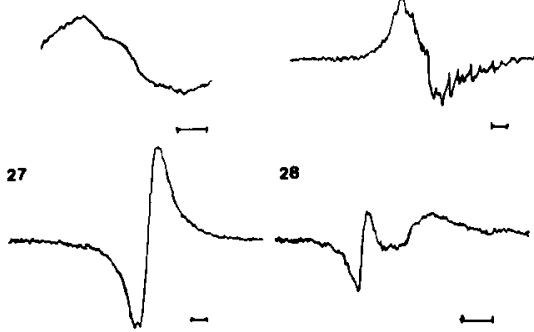

29

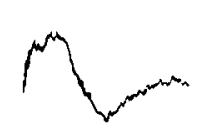

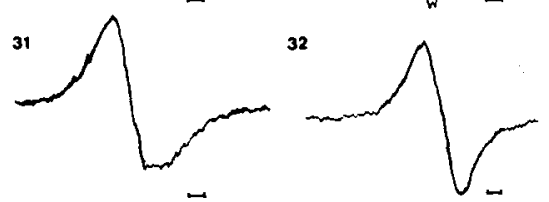

37

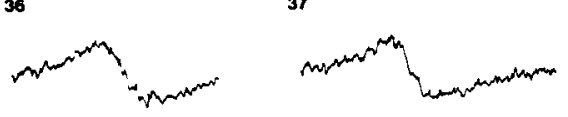
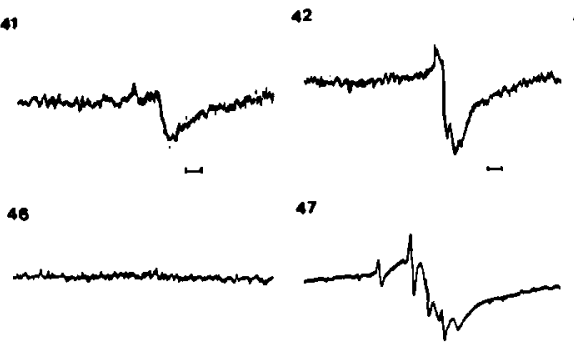

$\varpi$

Neth. J. agric. Sci. 27 (1979)
33

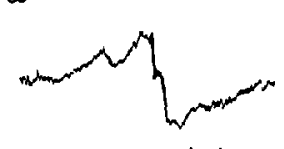

38 N phatm

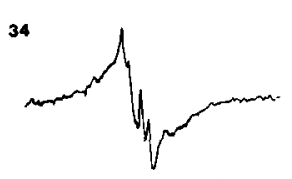

30
30
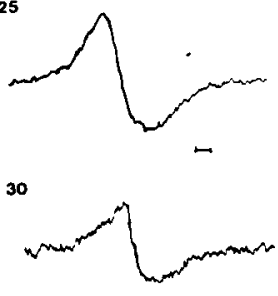

$\mapsto$
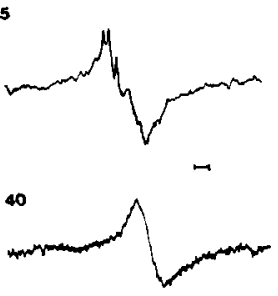

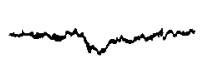

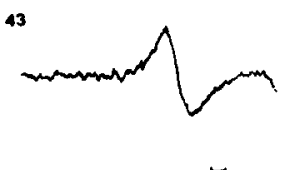
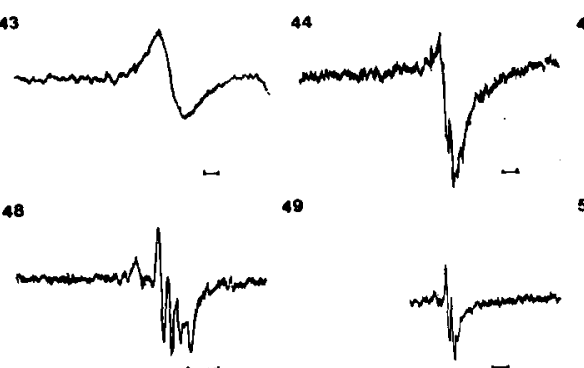

45
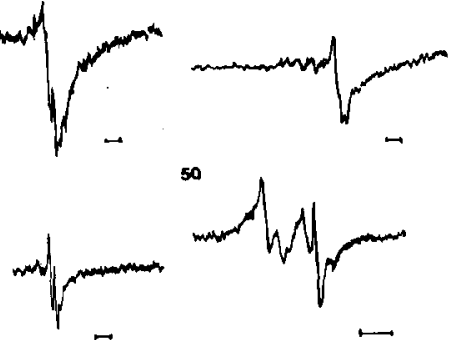
Fig. 1-50. Legends to the spectra.

Lignin

Fig. 1. 'Meadol', $1 \%$ in $0.1 \mathrm{~N} \mathrm{NaOH}$.

Humic acids

Podzol- $B_{h}$ horizon. Fig. 2: original HA, powder; Fig. 3: original HA, $1 \%$ in $1.0 \mathrm{~N} \mathrm{NaOH}$; Fig. 4: ABHA, $1 \%$ in $0.1 \mathrm{~N} \mathrm{NaOH}$; Fig. 5: ABHA, $1 \%$ in $0.1 \mathrm{NaOH}$, modulation amplitude high; Fig. 6: ABHA, $1 \%$ in $0.1 \mathrm{~N} \mathrm{NaOH}$, flushed with argon; Fig. 7: ABHA, $1 \%$ in $N \mathrm{NaOH}$, flushed with $\mathrm{O}_{2}$; Fig. 8: ABHA, $1 \%$ in $0.1 \mathrm{~N} \mathrm{NaOH}, \mathrm{H}_{2} \mathrm{O}_{2}$ added; Fig. 9: ABHA, $1 \%$ in $0.1 \mathrm{~N} \mathrm{NaOH}, \mathrm{H}_{2} \mathrm{O}_{2}$ added for 2 hours; Fig. 10: ABHA, $1 \%$ in $0.1 \mathrm{~N} \mathrm{NaOH}$, dithionite added; Fig. 11: original $\mathrm{HA}, 3 \%$ in $0.1 \mathrm{~N} \mathrm{NaOH}$, low power, high concentration; Fig. 12: original $\mathrm{HA}, 1 \%$ in $1.0 \mathrm{~N} \mathrm{NaOH}$, power normal, low concentration, high titre; Fig. 13: original HA, $3 \%$ in $1.0 \mathrm{~N} \mathrm{NaOH}$, low power, high concentration, high titre; Fig. 14: original HA, $3 \%$ in $1.0 \mathrm{~N} \mathrm{NaOH}$, solution of Fig. 13 after standing for $16 \mathrm{~h}$; Fig. 15: original HA, $3 \%$ in $4.0 \mathrm{~N}$ $\mathrm{NaOH}$, high concentration, very high titre; Fig. 16: original HA, $3 \%$ in $4.0 \mathrm{~N} \mathrm{NaOH}$, flushed with argon; Fig. 17: original $\mathrm{HA}, 3 \%$ in $4.0 \mathrm{~N} \mathrm{NaOH}$, flushed with $\mathrm{O}_{2}$; Fig. 18: original $\mathrm{HA}$, $3 \%$ in $0.1 \mathrm{~N} \mathrm{NaOH}$, low titre, flushed with argon; Fig. 19: original $\mathrm{HA}, 3 \%$ in $0.1 \mathrm{~N} \mathrm{NaOH}$, low titre, flushed with $\mathrm{O}_{2}$; Fig. 20: original $\mathrm{HA}, 3 \%$ in $0.1 \mathrm{~N} \mathrm{NaOH}$, flushed with air; Fig. 21: original $\mathrm{HA}, 1 \%$ in $0.1 \mathrm{~N} \mathrm{NaOH}$, low titre, low concentration, flushed with air; Fig. 22: original $\mathrm{HA}, 1 \%$ in $0.1 \mathrm{~N} \mathrm{NaOH}$, low titre, low concentration, flushed with $\mathrm{O}_{2}$; Fig. 23: original HA, n.d., dimethyl sulfoxide + trimethanolamine.

Dopplerite. Fig. 24: original HA, n.d., in $1.0 \mathrm{~N} \mathrm{NaOH}$; Fig. 25: original HA, n.d., in $0.1 \mathrm{~N}$ $\mathrm{NaOH}$, treated with $\mathrm{H}_{2} \mathrm{SO}_{4}-\mathrm{HCl}$; Fig. 26: ABHA, n.d., in $0.5 \mathrm{~N} \mathrm{NaOH}$; Fig. 27: ABHA, n.d., in $1.0 \mathrm{~N} \mathrm{NaOH}$, treated with $2 \% \mathrm{HNO}_{3}$; Fig. 28: ABHA, n.d., in $1.0 \mathrm{~N} \mathrm{NaOH}$, solution of Fig. 27 with addition of dithionite.

Tilt chernozem. Fig. 29: original HA, n.d., in $1.0 \mathrm{~N} \mathrm{NaOH}$; Fig. 31: ABHA, n.d., in $1.0 \mathrm{~N}$ $\mathrm{NaOH}$.

'Hackfort'. Fig. 30: original HA, n.d., in 1.0 N NaOH; Fig. 32: ABHA, n.d., in $1.0 \mathrm{~N} \mathrm{NaOH}$. Tannins etc. Fig. 33: mimosa tannin, original, commercial powder, in $0.1 \mathrm{~N} \mathrm{NaOH}$; Fig. 34: mimosa tannin, phlobaphenes, obtained by $\mathrm{HCl}$ refluxing, in $1.0 \mathrm{~N} \mathrm{NaOH}$; Fig. 35: flavan derivative, dl-catechin, boiled with $6 \mathrm{~N} \mathrm{HCl}$, in $0.1 \mathrm{~N} \mathrm{NaOH}$; Fig. 36: mimosa tannin, original powder treated with $2 \% \mathrm{HNO}_{3}$, in $0.1 \mathrm{~N} \mathrm{NaOH}$; Fig. 37: flavan derivative, dl-catechin treated with $2 \% \mathrm{HNO}_{3}$, in $0.1 \mathrm{~N} \mathrm{NaOH}$; Fig. 38: mimosa powder phlobaphenes, treated with $2 \% \mathrm{HNO}_{3}$. followed by sodium dithionite, in $1.0 \mathrm{~N} \mathrm{NaOH}$; Fig. 39: oak leaves, green, methanol extract without chlorophyl, dried, after boiling with $6 \mathrm{~N} \mathrm{HCl}$, in $8.0 \mathrm{~N} \mathrm{NaOH}$; Fig. '40: oak leaves, green, freeze-dried, the alcohol/benzol extract, from this the $\mathrm{CHCl}_{3}$-insoluble part, in $1.0 \mathrm{~N} \mathrm{NaOH}$; Fig. 41: oak leaves, yellow-brown, the residue after extraction with alcohol/ benzol, water, and ethyl acetate respectively, in $1.0 \mathrm{~N} \mathrm{NaOH}$; Fig. 42: oak leaves, yellowgreen, as Fig. 40, after boiling with $6 \mathrm{~N} \mathrm{HCl}$, in $1.0 \mathrm{~N} \mathrm{NaOH}$; Fig. 43: oak leaves, yellowbrown, the residue as Fig. 41, after boiling with $6 \mathrm{~N} \mathrm{HCl}$, in $1.0 \mathrm{~N} \mathrm{NaOH}$; Fig. 44: oak leaves, yellow-brown, the alcohol/benzol extract without chlorophyl, after boiling with $6 \mathrm{~N} \mathrm{HCl}$, in $1.0 \mathrm{~N} \mathrm{NaOH}$; Fig. 45: oak leaves, yellow-brown, the water extract, after benzol/alcohol extraction, after boiling with $6 \mathrm{~N} \mathrm{HCl}$, in $1.0 \mathrm{~N} \mathrm{NaOH}$; Fig. 46: oak leaves, yellow-brown, the chlorophyl fraction after boiling with $6 \mathrm{~N} \mathrm{HCl}$, in $1.0 \mathrm{~N} \mathrm{NaOH}$; Fig. 47: oak leaves, green, compound $\mathrm{A}$ obtained by $\mathrm{TIC}$, in $1.0 \mathrm{~N} \mathrm{NaOH}$; Fig. 48: oak leaves, green, compound $\mathrm{F}$ obtained by TlC, in $1.0 \mathrm{~N} \mathrm{NaOH}$; Fig. 49: oak leaves, green, compound $\mathrm{E} / \mathrm{D}$ obtained by TlC, in $1.0 \mathrm{~N} \mathrm{NaOH}$; Fig. 50: humic acid, podzol- $\mathrm{B}_{\mathrm{h}}$, untreated, $1 \%$, in $1.0 \mathrm{~N} \mathrm{NaOH}$.

$(\mathrm{HA}=$ humic acid; $\mathrm{ABHA}=$ acid-boiled-humic acid; TIC $=$ thin-layer chromatography; n.d. $=\%$ not determined.)

contrast to this, a curve is shown without any hyperfine splittings (Fig. 2) by dry powdery humic acids- $B_{h}$-podzol. This is in conformity with Tollin et al. (1963) and also occurs at $77 \mathrm{~K}$. In the original ca. $1 \% \mathrm{HA}^{-B_{\mathrm{h}}}$ spectra in $1 \mathrm{~N} \mathrm{NaOH}$, saturation symptoms develop rapidly. With a power of $0.25 \mathrm{~mW}$ the details can best be 
question, though the symptom is identical with that of the former substance. By further treatment with strong acids, nearly all spectral structures in the phlobaphenes are lacking because of the difficult solubility. Untreated catechin does not show any EPR signal; the free radicals are a result of condensation or polymerization. Condensations through acids have been shown by Byung-Zun-Ahn \& Gstirner (1970). The presence of dimers and trimers in nature, as well as a possible spiral structure, is also described by Byung-Zun-Ahn (1974).

\section{Leaf constituents}

Shortly before leaf fall, extracts are obtained from green and yellow-brown oak leaves having the characteristics of a tannin and of a radical as well. These symptoms are observed in the methanolic extract (Fig. 39) as well as in the alcohol-benzol extract and then mainly in the fraction which does not dissolve in $\mathrm{CHCl}_{3}$ (Fig. 40). The same applies to the leaf rests which are left after exhaustive extractions, but then with a very weak signal (Fig. 41) and also after hydrolization of the different extracts with $6 \mathrm{~N} \mathrm{HCl}$ (Figs. 42 to 45 incl.). No radical signal in the chlorophyl fraction can be found, even after boiling with $6 \mathrm{~N} \mathrm{HCl}$ (Fig. 46). All these spectra are simple curves without remarkably fine structures. They can be found, however, in a number of separate tannin compounds which, through chromatographic technique, have been isolated from the extracts, the compounds $\mathrm{A}, \mathrm{F}$ and mixture $\mathrm{D} / \mathrm{E}$ (Figs 47,48 and 49 ). In their spectrum the first two are greatly similar to humic acid from podzol $B_{h}$ (Figs 12 and 50), though the breadth of the signal greatly differs; viz 1.1 to $2.1 \mathrm{G}$.

\section{Discussion}

The influence of oxygen and the action of dithionite indicate a radical which contains oxygen or is highly sensitive to it and shows redox reactions. In the analysed substances we have to do with a long-living stable radical-containing nucleus which is present in all humic acids and contains at least one free electron, considering the smooth curves. A number of aliphatic chains can then be suspended from this nucleus in which the free electrons come into interaction with different kinds of protons, causing the hyperfine structure. The idea of suspending chains has been based upon the easy overpowering of the signal. A clear relation exists between the applied power and the signal being dependent on concentration and titre. It was found that the influence of mineral acids upon different substances highly differed. Treating tannin with diluted $\mathrm{HCl}$ a substance is formed showing a spectrum with hyperfine structure (Figs 33 and 34). This symptom also occurs if, for instance, catechin is boiled with $6 \mathrm{~N} \mathrm{HCl}$ (Fig. 35). A similar treatment does not remove the fine structure in the humic acid of the podzol- $\mathrm{B}_{\mathrm{h}}$ (Figs 3 and 4), but it does not develop this either in other humic acids (Figs 24 and 26, 29 and 31, 30 and 32 ). The intensification of the signal after dopplerite has been boiled with $2 \%$ $\mathrm{HNO}_{3}$ (Figs 26 and 27), indicates an increase in the number of free electrons just as in mimosa tannin (Figs 33 and 36). By adding dithionite the intensity of the signal in both substances decreases (Figs 27, 28, 34 and 38) and the fine structure 
as well. A different form of the spectrum originates; the form of the double-topped dopplerite spectrum strongly resembles that of $A B H A-B_{h}$ after having been treated with dithionite (Fig. 10). Without further knowledge of the molecular construction of these condensed substances, a further penetrating analysis of all these spectra is impossible. In view of the little encouraging results to find the building stones of the humic acid through destruction (oxidation or reduction), it would be useful to try to derive the construction of the humic acid by a synthetic approach. It seems to be the best way to proceed from the idea that the humic acids are already induced in the plants and that therein the forerunners, i.e. the hardly condensed primordial polymers of the humic acids, develop condensates with only a few monomers which may even be of different structures. Assuming that the free radical is the humic acid molecule itself or that free radicals are loosely bound to it, the question arises where these radicals come from. Commoner et al. point out that in much vegetable material, free radicals were found to be developed by light. The question is what compounds will come under consideration to form humic acids. Waksman's old idea that the protein-lignin complex would form the humic acids, seems not very relevant. The lignin content in the green leaves and in the litter of trees does not or hardly differ. This indicates that, with any complex formation of lignin and protein, the band between these substances is not strong. Should Wakman's hypothesis be right, then it is certain that a much stronger humic acid accumulation would take place in the soil than now (Minderman, 1968). The idea of Swaby \& Ladd (1962) that, after dying off, the humic acids are formed in the plant cells as indistinct complexes, has been stated too generally. It is certain that, within a short time, carbohydrates, lignin and proteins will mainly have been converted and mineralized in the soil. The greater part of the organic matter in a natural soil consists of humic acids, in a broad sense. From a model investigation into the way and the time needed to ascertain the quantity of organic matter heaped up upon and down into the soil as is locally found in nature, it became clear that only a small part of the quantity of the leaves and branches annually added to the soil, are needed (Minderman, 1968). Humic acids can hardly be affected by micro-organisms; this can be read off from the stipulation of the average stay of the humic acids by means of ${ }^{14} \mathrm{C}$ dating from 200 to 5000 years (Campbell et al., 1967; Scharpenseel \& Pietig, 1969). What combinations can last such a long time?

I have found that polymerization products of tannins can hardly be used by micro-organisms, or not at all. In enrichment cultures with soil, there is some $\mathrm{CO}_{2}$ production for only a short time, coming to a standstill after a few weeks. The stated accumulation of organic matter and humic acids in natural soils can be explained by the quantities of tannin found in many tree leaves. A content of, for instance, about $5 \%$, is sufficient to cause the accumulation found in nature of hard to be affected humic compounds (Minderman, 1968).

Apart from the compounds to be characterized as tannin, i.e. substances which can be fixed by skin powder, numerous compounds occur in the leaves which can be considered to take part in the structure of the condensates, such as polyhydroxy acids, polyphenols and flavanoid substances. We shall first confine ourselves to the real tannins and then in particular to those substances the structure of which can 
be derived from catechin. (These tannins are found in large quantities in Acacia and Eucalyptus species, and to a lesser extent, in leaves and bark of oak trees, beech trees and chestnut trees; Hathway, 1962.)

When we compare the EPR spectra of the tannin mimosa and catechin, and the spectra of leaf constituents with hyperfine structure and with humic acid from podzol- $\mathrm{B}_{\mathrm{h}}$, not only differences can be stated but also similarities of a regularity not to be ignored. In other substances where only a smooth EPR curve is found, form and size are almost identical with the humic acids from, for example, Oxbow and Hackfort I. As far as useful, reference is made to the difference in the splitting factor, which in humic acids amounts from 2.005 to 2.008 and in leaf constituents to about 2.014. Whether these differences are essential or not, cannot be made out from the present material. Though all substances with a hyperfine structure are highly similar to the behaviour of Coppinger's radical with regard to reduction and oxidation (Walker, 1961), the line is so much thinner that a free semi-quinone structure may not be deduced without anything more; we must rather think of structural occlusion of the electron by surrounding and enclosing small groups. As the spectrum of not a single, simple compound is fully similar to the spectrum of humic acids, this will lead to the idea that these humic acids do not consist of one, but of more compounds in which summation and interference of their spectra lead to the spectrum of humic acid. It was found that, through EPR spectrum analysis, the existence of compounds or groups of compounds with more or less identical radical spectra could be proved in the range green leaves to humic acids from different soils. From the affinity of the spectra of humic acids with those of a number of plant constituents, as catechin, mimosa tannin, extracts of green and brown leaves and compounds isolated from green leaves, it may be gathered that the humic acids may have been formed of these building stones. The basic structures of these substances are those of flavan or mixed esters from aromatic hydroxy acids and aliphatic alcohols, such as sugars. The latter group is frequently found in hydrolysable tannins, especially the ellagitannins, which, on hydrolysis, produce ellagic acid and sugars. The substances we isolate from oak leaves belong to this group and can be characterized as esters of hexahydroxydiphenic acid with glucose and some xylose. On hydrolysis, the diphenic acid changes into its lacton form, the ellagic acid. Such mixed esters can hardly be affected by microbes; they counteract oxidation (Forgo, 1969) and promote the formation of stable radicals or preserve these (Rennov \& Mochalkin, 1972). Furthermore, the presence of sugars in humic acids which are difficult to release (Cheshire et al., 1967; Haworth, 1971) could immediately be explained. Sugars also occur in condensed tannins, but then they are, through ether bridges, bound to flavan derivates and can hardly be broken down by microbes. When humic acids are formed out of the building stones mentioned, it must not be excluded that polymeric chains may be formed. ByungZun-Ahn (1974) assumes that the polymers of the catechins he has found, show a spiral structure which would be of importance in tanning spiral built proteins. A spiral-formed chain formation in the above mentioned mixed esters is quite well possible, if every glucose molecule is connected with two separate diphenic molecules. With sufficient hydrogen bridges, these chains form solid, directed 
structures, most probably spirals with interstitial distances, equal to those of the proteins $(0.6 \mathrm{~nm})$.

\section{Conclusions}

The EPR research shows that all humic acids have a more or less strong radical character. Only humic acids from the $B_{h}$ horizon of podzol show a hyperfine structure. The behaviour towards reduction and oxidation in humic acids is similar to that of tannins, in a broad sense. The character of dopplerite and its hydrolytic products deviates from $B_{h}$ humic acids, because here the pure dopplerite is difficult to dissolve in $\mathrm{NaOH}$ whereas the hydrolysed product does easily. As a whole, the characteristics in our research correspond with those stated in humic acids by Atherton et al. (1967). Hydrolysable tannins occur in oak leaves, consisting of mixed esters of a known structure belonging to the ellagitannins, having a radical character, and which, in spectral qualities greatly correspond with humic acids. They may differ from the latter in the smaller line breadth of the spectra, though, in humic acids, this does not seem to be a constant factor either. It may be deduced from the spectra that humic acids are no homogeneous polymers but consist of more compounds; the EPR spectrum must be regarded as a collective spectrum of different components. As components are considered the tannins which, through new bonds of the aromatic hydroxyl groups and through hydrogen bridges, transfer into insoluble compounds hard to be affected. The presence of stable radicals can be explained by the structure of the mixed esters, several of which are known to work radically preserving. Based on the results of the EPR research, indications exist, which, in Part 2 of this study, will still be supported by an infra-red and chemical analysis, namely that humic acids may develop from tannins, in a broad sense, by means of polymerization into microbially, practically unaffectable, waterinsoluble compounds, of which one part of the molecule is aromatic and the other part consists of carbohydrate residues.

\section{Acknowledgment}

First of all I am deeply grateful to Drs H. J. Grande of the Department of Biochemistry of the Agricultural University of Wageningen who made the EPR spectra for me and with me and also gave me highly valuable directions. I further want to express my thanks to Prof. Dr E. A. Paul, Saskatoon, Canada, for sending soil samples, and to my colleagues for their constructive criticism of the results.

\section{References}

Atherton, N. M., P. A. Cranwell, A. J. Floyd \& R. D. Haworth, 1967. Humic acid. I. E.S.R. spectra of humic acids. Tetrahedron 23: 1653-1667.

Brauns, F. E., 1952. The chemistry of lignin. Academic Press, New York.

Burges, A. \& P. Latter, 1960. Decomposition of humic acid by fungi. Nature, Lond. 186: 404.

Byung-Zun-Ahn, 1974a. Ein Catechintrimer aus der Eichenrinde. Arch. Pharmaz. 307: 186-197. 


\section{MOLECULAR STRUCTURE OF HUMIC ACIDS. 1}

Byung-Zun-Ahn, 1974b, Catechingerbstoffe aus der Tormentilla-Wurzel. Arch. Pharmaz. 307: 241-250.

Byung-Zun-Ahn \& F. Gstirner, 1970. Gewinnung von Catechin-Dimeren durch Säurekondensation. Arch. Pharmaz. 303: 720-725.

Campbell, C. A., E. A. Paul, D. A. Rennie \& K. J. McCallum, 1967. Applicability of the carbon-dating method of analyses to soil humus studies. Soil Sci. 104 (3): 217-223.

Cheshire, M. V., P. A. Cranwell, C. P. Falshaw, A. J. 'Floyd \& R. D. Haworth, 1967. Humic acid. II. Structure of humic acids. Tetrahedron 23: 1669-1682.

Commoner, B., J. Townsend \& G. E. Pake, 1954. Free radicals in biological materials. Nature 4432 (9 October): 689-691.

Forgo, I., 1969. Physikalisch-chemische Eigenschaften und Antioxydans-Wirkung einiger neuer Gallussäure-Ester-Derivate. Dissertation, ETH Zürich, No 4410, pp. 101.

Hathway, D. E., 1962. The condensed tannins. In: W. E. Hillis (Ed.), Wood extractives and their significance to the pulp and paper industries. Academic Press, New York.

Haworth, R. D., 1971. The chemical nature of humic acid. Soil Sci. 111: 71-79.

Hinney, B., 1972. Photochemische Reaktion der 4-Hydroxyzimtsäure. Gött. bodenk. Ber. No 24. Institut für Bodenkunde, Göttingen.

Hisey, W. O., 1946. Delignification of wood. In: L. E. Wise (Ed.), Wood chemistry, Vol 1-x. Reinhold, New York, $900 \mathrm{pp}$.

Kleinert, T. N. \& J. R. Morton, 1962. Electron spin resonance in wood grinding and wood pulping. Nature 196: 334-336.

Minderman, G., 1968. Addition, decomposition and accumulation of organic matter in forests. J. Ecol. 56: 355-362.

Rennov, A. V. \& A. J. Mochalkin, 1970. Biofizika 15 (5): 863-866. In: Biol. Abstr. 53 (9) (1972): 51660.

Rex, R. W., 1960. Electron paramagnetic resonance studies of stable free radicals in lignins and humic acids. Nature 4757 (31 December): 1185.

Riffaldi, R. \& M. Schnitzer, 1972a. Electron spin resonance spectrometry of humic substances. Proc. Soil Sci. Soc. Am. 36: 301-304.

Riffaldi, R. \& M. Schnitzer, 1972b. Effects of diverse experimental conditions on E.S.R. spectra of humic substances. Geoderma 8: 1-10.

Scharpenseel, H. W. \& F. Pietig, 1969. Altersbestimmung von Böden durch die Radiokohlenstoffdatierungsmethode. III. Z. PflErnähr. Bodenk. 122: 145-152.

Slavinska, D., J. Slavinski \& I. Sarna, 1975. The effect of light on the E.S.R. spectra of humic acids. J. Soil Sci. 26 (2): 93-99.

Steelink, C., 1964. Free radical studies of lignin, lignin degradation products and soil humic acids. Geochim. cosmochim. Acta 28: 1615-1622.

Steelink, C., 1965. Stable phenoxy radicals derived from phenols related to lignin. J. Am. chem. Soc. 87: 2056-2057.

Steelink, C. \& G. Tollin, 1962. Stable free radicals in soil humic acid. Biochim. biophys. Acta 59: 25-34.

Steelink, C., F. Reid \& G. Tollin, 1963. On the nature of the free-radical moiety in lignin. J. Am. chem. Soc. 85: 4048.

Swaby, R. J. \& J. N. Ladd, 1962. Chemical nature, microbiological resistance and origin of soil humus. Trans, int. Soil Conf. int. Soc. Soil Sci. (New Zealand), Comm. 4 \& 5: 3-8.

Tollin, G., T. Reid \& C. Steelink, 1963. Structure of humic acid. IV. Electron paramagnetic resonance studies. Biochem. biophys. Acta 66: 444-447.

Tollin, G. \& C. Steelink, 1966. Biological polymers related to catechol E.P.R. and I.R. studies of melanin, tannin, lignin, humic acid and hydroxyquinones. Biochim. biophys. Acta 112: 377-379.

Walker, S. \& H. Straw, 1961. Spectroscopy, Vol. 1. Chapman \& Hall, London.

Waksman, S. A., 1936. Humus. Williams \& Wilkins, Baltimore, 494 pp. 